\title{
EFEITO MUTAGÊNICO DA PLANTA COFFEA ARÁBICA L. NAS CÉLULAS DA MEDULA ÓSSEA DE RATOS WISTAR
}

Hamilton de Castilho Magalhães Silva

Universidade do Oeste Paulista - UNOESTE, curso de Biomedicina, Presidente Prudente, Sp. E-mail: hamiltonmagalhaessilva@hotmail.com

\section{RESUMO}

O presente estudo teve como objetivo avaliar o potencial efeito mutagênico do café. O material genético é constantemente exposto a vários agentes artificiais e naturais, que podem acarretar em uma mutação. $O$ café é importante alimento consumido mundialmente, porém já que contém substâncias que podem acarretar em uma mutação, torna-se importante o estudo sobre os possíveis efeitos mutagênicos. Neste estudo foram analisados, por meio de testes ex vivo em ratos Wistar, eritrócitos micronucleados, através do ensaio do micronúcleo, lâminas de células de medula óssea desses roedores. A análise dos dados mostrou que os diferentes tratamentos testados não induziram micronúcleos sobre eritrócitos policromáticos, no entanto os animais que receberam a infusão a $1 \%$ de café consumiram significativamente maior quantidade de infusão em relação aos animais que receberam 5 e $10 \%$. Conclui-se que consumo de café em quantidades moderadas não é capaz de induzir efeitos mutagênicos.

Palavras-chave: café, genotóxico, micronúcleo, mutação, cafeína.

MUTAGEN EFFECT OF COFFEA ARABICA L. PLANT IN BONE MARROW CELLS OF WISTAR RATS.

\section{ABSTRACT}

This study aimed to evaluate the potential mutagenic effects of coffee. Our genetic material is constantly exposed to various natural and artificial agents which may result in a mutation. The coffee is an important beverage consumed worldwide, however it contains substances that may cause a mutation, therefore it is important to study the possible mutagenic effects of coffee. In this study ex vivo erythrocytes of bone marrow cell from rats were analyzed by using the micronucleus test. The data analysis shows that different treatments did not induce micronuclei of polychromatic erythrocytes, however animals that received infusion of $1 \%$ of coffee consumed significantly greater amount of infusion than animals that received $5 \%$ and $10 \%$. The conclusion was that coffee consumption in moderate amounts is not capable of inducing mutagenic effects.

Keywords: Coffee, genotoxic, micronucleus, mutation, caffeine.

\section{INTRODUÇÃO}

O café é um dos produtos mais importantes do Brasil. O país é o primeiro produtor e o segundo consumidor mundial do produto. $O$ consumo de café por pessoa no Brasil $(6,4 \mathrm{Kg} /$ por habitante ano) bateu recorde em fevereiro de 2013, sendo o maior já registrado no país desde 1965, e tem se mantido estável nos últimos anos, segundo a Abic (Associação Brasileira da Indústria de Café) $)^{1,2}$.

Muitas revisões têm considerado o potencial mutagênico do café em vários sistemas biológicos, tais como bactérias, leveduras e em cultura de células de mamíferos ${ }^{3-5}$. Testes in vitro demonstraram que a cafeína, presente em cafés e chás, afeta a ação reparadora do DNA durante a divisão celular, modificando a resposta apoptótica e alterando o funcionamento do gene p53, que codifica uma proteína reguladora do ciclo celular ${ }^{6,7}$.

Nehlig et al. ${ }^{4}$ obtiveram resultados que demonstraram que o café é clastogênico pela inibição de mecanismos de reparo, seguido de excisão, fotorreativação pós-replicação, diminuição do tamanho do repiclon, inibição, elongação e formação do intervalos de DNA transformante ${ }^{4}$. 
Estudos científicos corroboraram que as mulheres, durante a gestação, devem diminuir consideravelmente o consumo de café, pois a depuração da cafeína fica alterada durante a gravidez, sobretudo no segundo e terceiro trimestres, quando a meia-vida da cafeína é de cerca de 7 e 10 horas, enquanto que, em mulheres não-grávidas é de 2,5 a 4,5 horas. Este aumento da meia-vida da cafeína nas mães coincide com o período durante o qual o desenvolvimento fetal é exponencial e o acumulo desta substância poderia representar potenciais riscos para o feto, tais como: baixo peso ao nascer, retardo de crescimento uterino, aborto espontâneo e aumento do risco de ruptura precoce das membranas ${ }^{8,9}$.

$\mathrm{O}$ crescimento das taxas de morbidade e mortalidade perinatal e neonatal tem acontecido devido, sobretudo, à ausência, no feto, de enzimas necessárias para a demetilação da cafeína, deixando-o exposto por um longo período da vida intrauterina a esta substância ${ }^{10,11}$. Outros estudos relatam também que, durante a gestação, a cafeína aumenta as concentrações de catecolaminas no sangue, e esses hormônios acarretam efeitos negativos para o feto, em virtude da vasoconstrição e da hipóxia fetal ${ }^{12,13}$.

$\mathrm{O}$ teste do micronúcleo tem sido amplamente usado tanto in vitro quanto in vivo como um teste primário em genética toxicológica, pela sua capacidade de avaliar genotoxidade $^{14,15}$. Os micronúcleos são fragmentos cromossômicos ou cromátides acêntricas e de cromossomos inteiros, que não são incorporados no núcleo da célula filha durante a divisão celular. Eles são corpúsculos contendo DNA sem qualquer conexão estrutural com o núcleo principal ${ }^{16}$.

A presença de micronúcleos pode ser considerada um indicativo prévio da existência de alterações cromossômicas, por isso, a análise de sua frequência vem a ser proposta como uma alternativa para métodos clássicos em monitoramento de danos cromossômicos, podendo ser empregada para detectar efeitos citogenéticos em indivíduos cronicamente exposto a agentes mutagênicos e/ou carcinogênicos ${ }^{15,16}$.

Como o café possui uma mistura complexa de diferentes moléculas com atividade genotóxica, como: o metilglioxal, o peróxido de oxigênio e os dicarbonos alifáticos, formados durante o processo de torrefação e, múltiplas análises mostraram que o café induz a mutações Colloq Vitae2017 set-dez; 9(3): 36-39. DOI: 10.5747/cv.2017.v09.n3.v207 ISSN 1984-6436/C 2017 - Publicado pela Universidade do Oeste Paulista. Artigo Open Access sob uma licença CC BY-NC-ND (http://creativecommons.org/licenses/by-nc-nd/4.0/). em várias cepas de Salmonella typhimurium, em células de hamster chinês e em linfócitos humanos ${ }^{17}$, é importante analisar o potencial mutagênico do café.

Portanto, este trabalho possui como objetivo a investigação de possíveis danos genéticos, decorrentes da exposição a grandes doses de café no organismo, através do teste do micronúcleo em ratos Wistar, avaliando a potencialidade citotóxica, genotóxica e mutagênica do café no consumo cotidiano.

\section{METODOLOGIA}

O experimento foi realizado no Biotério experimental e Laboratório de Genética Molecular da Universidade do Oeste Paulista UNOESTE.

Foram utilizados 20 ratos Wistar, em idade adulta, pesando aproximadamente $250 \mathrm{~g}$, divididos em quatros grupos com cinco animais cada. Os ratos foram pesados e, mantidos em caixas individuais com bebedouro e comedouro, com livre acesso à ração, em condições adequadas (umidade de $55 \%$, temperatura ambiente de $27^{\circ}$ e ciclo de $12 \mathrm{~h}$ luz - $12 \mathrm{~h}$ escuro). Um grupo recebeu água ad libitum no bebedouro, e o outros, diferentes concentrações $(1,5$ e $10 \%)$ de café. Ou seja, ao invés de água receberam somente café ad libitum para beber, em uma situação experimental de ingestão prolongada de café. Este estudo foi aprovado pelo Comitê de Ética no Uso de Animais - CEUA (protocolo no 2347) da Universidade do Oeste Paulista - UNOESTE.

O café foi preparado em 1,5 e $10 \%$, onde foi adicionada água fervente. Essa infusão foi mantida por 15 minutos e, em seguida, filtrada. Durante 19 dias, foi colocado o café no bebedouro no período da manhã até à tarde, no período noturno foi colocado água ad libitum e em um período de 7 horas foi restringido o acesso ao bebedouro.

As coletas para a análise do micronúcleo foram efetuadas no 19o dia, com auxilio de agulhas e seringas. Foi coletado o sangue medular de cada animal, transferindo o material para tubos vacutainer com anticoagulante EDTA. Para cada animal foram preparadas três lâminas com a técnica do esfregaço. As lâminas foram secadas em temperatura ambiente durante 24 horas, fixadas em metanol por 5 min e coradas com solução de Giemsa.

Foram avaliados 3000 eritrócitos policromáticos (EP) por animal (1000/lâmina), 
para o registro da frequência de eritrócitos policromáticos micronucleados (PCEMNs). As análises foram feitas em microscópio óptico (1000 x) com óleo de imersão.

Os parâmetros foram analisados por ANOVA, seguidos do teste de Tukey, para identificar as diferenças entre os grupos. Os tratamentos foram considerados diferentes estatisticamente quando $p<0,05$.

\section{RESULTADOS}

De acordo com a Tabela 1, não houve diferença significativa entre os tratamentos para o número de micronúcleos e peso dos animais antes e depois do período experimental. Por outro lado, observa-se que os animais do grupo $1 \%$ consumiram significativamente maior quantidade de infusão em relação aos grupos $5 \%$ e $10 \%$ que ingeriram menor quantidade de infusão $(p<0,0001)$.

Tabela 1. Número de micronúcleos, peso dos animais antes e após o período experimental e consumo de infusão pelos ratos submetidos aos tratamentos durante 19 dias.

\begin{tabular}{lcccc}
\hline Tratamentos & Micronúcleos & Peso antes & Peso depois & Consumo \\
\hline Controle & $1,40 \pm 0,59$ & $189,13 \pm 27,39$ & $181,95 \pm 20,50$ & - \\
Infusão 1\% & $1,87 \pm 0,77$ & $153,95 \pm 18,73$ & $187,19 \pm 13,84$ & $490,20 \pm 17,80^{\text {a }}$ \\
Infusão 5\% & $2,00 \pm 0,85$ & $177,93 \pm 27,54$ & $194,59 \pm 17,38$ & $337,20 \pm 47,30^{\text {b }}$ \\
Infusão 10\% & $1,80 \pm 0,61$ & $185,58 \pm 10,82$ & $183,45 \pm 6,96$ & $255,20 \pm 36,07^{\text {c }}$ \\
\hline p & 0,5887 & 0,0924 & 0,5901 & $<0,0001$
\end{tabular}

Letras diferentes na coluna indicam diferenças entre os grupos.

\section{DISCUSSÃO}

Os resultados mostram que os diferentes tratamentos testados não induziram micronúcleos sobre eritrócitos policromáticos.

Sabe-se que o café e a cafeína são mutagênico em concentrações elevadas em bactérias, leveduras e em cultura de células de mamíferos in vitro ${ }^{3,4}$. No entanto, o café e a cafeína não teve os mesmos efeitos em animais mutagênicos ex vivo ${ }^{4}$.

A acrilamida é classificada como uma substância provavelmente carcinogênica em humanos ${ }^{18}$, porém a quantidade de acrilamida encontrada no café torrado é relativamente baixa em relação ao potencial de formação resultante da presença abundante de asparagina e de açúcares redutores ${ }^{19}$.

O café também atua como um antioxidante, reduzindo o efeito citotóxico e mutagênico, há indícios de que a xantina presente no café é eficaz na inibição da oxidação do DNA, efeito mediado através da redução dos radicais adenina e guanina ${ }^{20}$.

Foi reportado em outro estudo efeito antimetastático da cafeína em um modelo de tumor de mamas em ratos ${ }^{21}$. De acordo com Abrahama e Stopperb ${ }^{22}$ o café instantâneo com cafeína pode exercer efeitos protetores in vitro em células de mamíferos contra danos no DNA, estas descobertas têm destacado o possível papel benéfico desta preparação de café como um agente protetor contra a genotoxicidade.
O consumo de uma xícara de café, em que se supõe a ingestão de $1-2 \mathrm{mg} / \mathrm{kg}$ de cafeína por peso corpóreo resulta em concentração plasmática máxima de 5-10 $\mu \mathrm{M}$. Um consumo excessivo (concentração plasmática $>50 \mu \mathrm{M}$ ) produz sintomas de cafeinismo (ansiedade, agitação, dificuldades de conciliar o sono, diarreia, tensão muscular, palpitações cardíacas). A dose letal $\left(D L_{50}\right)$ é de $150-200 \mathrm{mg} / \mathrm{kg}$ de peso corpóreo (concentração plasmática aproximada de $750 \mu \mathrm{M}$ ), que equivale ao consumo de uma só vez de 75 xícaras de café forte ${ }^{23}$. Levando em consideração a concentração de cafeína presente no café neste experimento, não houve uma ingestão expressiva de cafeína, o que leva a importância de novos estudos com o café em concentrações mais elevadas.

A investigação por meio do ensaio do micronúcleo, usada para avaliar a mutagenicidade do café consumido em moderadas quantidades, não obteve um resultado significativo em animais superiores, em comparação com alguns trabalhos encontrados na literatura, os quais demonstram potencial mutagênico do café e cafeína em organismos inferiores.

\section{CONFLITO DE INTERESSES}

Os autores declaram não haver qualquer potencial conflito de interesses que possa interferir na imparcialidade deste trabalho científico. 


\section{AGRADECIMENTOS}

Este estudo foi financiado pela Coordenação de Aperfeiçoamento de Pessoal de Nível Superior (CAPES).

\section{REFERÊNCIAS}

1. Associação Brasileira de Indústria de Café (ABIC). Estatísticas. Acesso: 2 fev 2018. Disponível em: http://abic.com.br/estatisticas/desempenho-do-setor/

2. Agricultura, Pecuária e Abastecimento. Acesso 11 maio 20175. Disponível em: http://www.agricultura.gov.br/vegetal/culturas/cafe/s aiba-mais.htm

3. Kihlman BA. Caffeine and chromossomes. Amsterdam: Elsevier; 1997.

4. Nehlig A, Debry G. Potencial genotoxic, mutagenic and antimutagenic effects of coffe: a review. Mutation Res. 1994;317:145-62. DOI: https://doi.org/10.1016/0165-1110(94)90022-1

5. Timson J. Caffeine. Mutation Res. 1977;47:1-52. DOI: https://doi.org/10.1016/0165-1110(77)90016-1

6. Mohr U, Emura M, Riebe-Imre M. Experimental studies on carcinogenicity and mutagenicity of caffeine. In: Garattini S. Caffeine, coffee and health. New York: Raven Press; 1993. p.359-78.

7. Ito K, Nakazato T, Miyakawa Y, Yamato K, Ikeda Y, Kizaki M. Caffeine induces G2/M arrest and apoptosis via novel p53 dependent pathway in NB4 promyelocytic leukemia cells. J Cell Physiol. 2003;196:276-83. DOI: https://doi.org/10.1002/jcp.10289

8. Bicalho GG, Barros Filho AA. Peso ao nascer e influência do consumo de cafeína. Rev Saúde Púb. 2002;36(2):180-7. DOI: https://doi.org/10.1590/S0034-89102002000200010

9. Brazier JL, Ritter J, Berland M, Khenfer D, Faucon G. Pharmacokinetics of caffeine during and after pregnancy. Dev Pharmacol Ther. 1983;6:313-22. DOI: https://doi.org/10.1159/000457332

10. Rondó PH, Rodrigues LC, Tomkins AM. Coffee consumption and intrauterine growth retardation in Brazil. Eur J Clin Nutr. 1996;50(11):705-9.

11. Institute of Medicine. Nutrition during pregnancy. Part I: weight gain, Part II: nutrient supplements. Washington: National Academy Press; 1990.

12. Bracken MB, Triche EW, Belanger K, Hellenbrand K, Leaderer BP. Association of maternal caffeine consumption with decrements in fetal growth. Am J Epidemiol. 2003;157(5):456-66. DOI: https://doi.org/10.1093/aje/kwf220
13. Bech BH, Obel C, Henriksen TB, Olsen J. Effect of reducing caffeine intake on birth weight and length of gestation: randomised controlled trial. BMJ. 2007;334(7590):409.

DOI: https://doi.org/10.1136/bmj.39062.520648.BE

14. Heddle JA, Hite MK, Mac Gregor JT, Neweell GW, Salamone MF. The induction of micronuclei as a measure of genotoxicity: a report of U.S. Environmental Protection Agency Gerle-Tox Program. Mutation Res. 1983;123:61-188. DOI: https://doi.org/10.1016/0165-1110(83)90047-7

15. Mac Gregor JT. Micronucleus assays protocols. Mutation Res. 1991;259:123-5. DOI: https://doi.org/10.1016/0165-1218(91)90116-4

16. Mristela J. O teste do micronúcleo: seu uso no homem. Biotemas. 1993;6(2):1-19.

17. Duarte MP, Laires A, Gaspar J, Leão D, Oliveira JS, Rueff J. Genotoxicity of instant coffee: possible involvement of phenolic compounds. Mutation Res. 1999;442:43-51. DOI: https://doi.org/10.1016/S13835718(99)00057-1

18. Arisseto AP, Toledo MCF. Acrilamida em alimentos: uma revisão. Braz J Food Technol; 2006;9(2):123-34.

19. Dias EC, Borém FM, Pereira RGFA, Soares $C$, Cunha $S$, Fernandes JO. Determinação dos níveis de acrilamida em cafés verdes obtidos por diferentes processamentos. VI Simpósio de Pesquisa dos Cafés do Brasil, 2008.

20. Kusano C, Ferrari B, Torres EAFS. Novos compostos dietéticos com propriedades anticarcinogênicas. Rev Bras Cancerol. 2002;48(3):375-82.

21. Yang $H$, Rouse J, Lukes L et al. Caffeine suppresses metastasis in a transgenic mouse model: a prototype molecule for prophylaxis of metastasis. Clin Exp Metastasis, 2004;21:719-35. DOI: https://doi.org/10.1007/s10585-004-8251-4

22. Abrahama SK, Stopperb H. Anti-genotoxicity of coffee against N-methyl-N-nitro-N-nitrosoguanidine in mouse lymphoma cells. Mutation Res. 2004;561:2333.

DOI:

https://doi.org/10.1016/j.mrgentox.2004.03.010

23. Carvalho JM, Maia GA, Sousa PHM, Rodrigues S. Perfil dos principais componentes em bebidas energéticas: cafeína, taurina, guaraná e glucoronolactona. Rev Inst Adolfo Lutz. 2006;65(2):7885 .

Recebido para publicação em 15/06/2016

Revisado em 16/06/2017

Aceito em 22/03/2018 